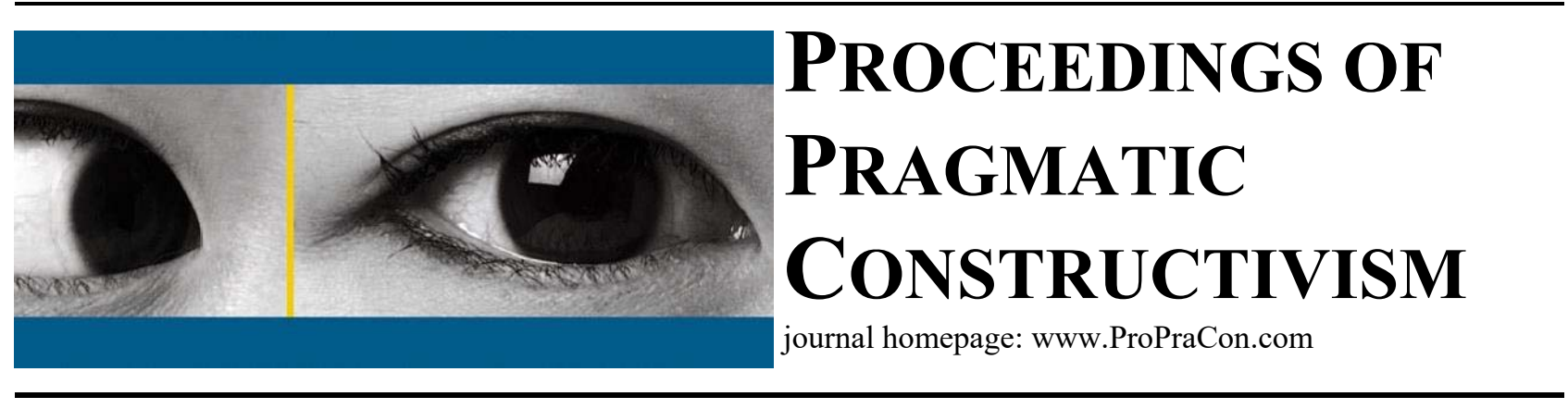

\title{
Language Games, Dialogue and the Other
}

\author{
Lars Bo Henriksen \\ Aalborg University, Department of Development and Planning \\ Rendsburggade 14, DK-9000 Aalborg, Denmark \\ E-mail:1bh@plan.aau.dk
}

\section{Introduction}

'How do we make a scientific account of a process that we are, ourselves, part of?'

(Student in a methodology class)

\section{Dialogue and Conceptualisation}

A bright student once asked: 'How do we make a scientific account of a process that we are, ourselves, part of?' This is a serious question for any empirical investigation in the social sciences and the student might not even have been aware of the depth and the seriousness of her question. This is an unavoidable problem in any social scientific research endeavour: the problem relates to the role of the researcher and the impact of the investigation itself. Firstly, let us look at the entire research enterprise; for whom are we doing research? For the sake of a personal career? For publishing academic papers in order to satisfy the university bureaucracy? Or could we, now that we are in the field, actually help and contribute something useful to the real people involved?

Why lie? We are there, we are in the field, we are part of the research process, we influence the process. When Latour wanted to observe an ant dragging a thread through a shell, one observes that we are dealing with two very different phenomena. One is a field of interest (the shell) and the other is a similar field, but now with an ant and a thread added to it (Latour, 1999, pp. 175-176). These are two very different things. We might as well admit, therefore, that we always have some influence on the social setting we are analysing. We cannot be a fly on the wall, a modest witness, an angel without wings having a God's eye perspective, or whatever. We are there in our bodily presence, with our language, our prejudices and our training as social scientists and it is, consequently, a whole new situation simply by our being there. Collecting data for social science research has a long history and an elaborated host of methods - a multitude of them. There is, however, another problem. What do we get from the interviews, observations, dialogues, field studies and so on? Do we learn something new or do we simply confirm our existing prejudices? Are we bringing, or imposing, certain languages and theories onto the focal research field? Or are we learning a new language? Are we solving problems or are we just creating new ones?

In order to respond to the initial question about our participation in the research process, I will, in this paper, investigate some very interrelated concepts - first language games and lifeworld and then the Other, dialogue and conceptualisation. Gadamer (1992) informed us that 'the entire experience of the world is linguistically mediated', therefore, when doing research we ourselves are part of, we obviously need to know the language games in order to get to know the lifeworld in question. So, this is my first investigation; Language games and life worlds. Also, when we do field work we encounter the Other. To get to know of language games and lifeworlds we need to talk to someone evidently - but how is that encounter? And what if we, instead of an interview, engaged in a dialogue? What would happen then? Might that solve some of the problems noted above? Would that make it easier for us to get to know about 
language games and lifeworlds? The basic idea here is that we, as researchers, through dialogues with the Other, get to know about their lifeworlds and language games: and further, we might even be able to contribute to the development of language games and lifeworlds through our research. I will start out here with a discussion of language games and lifeworlds; I then continue with a discussion about dialogue and the Other in order to present an analysis of the connections between them. Finally, I will return to the initial question: 'How do we make a scientific account of a process that we are, ourselves, part of?'.

\section{Language games and lifeworlds}

'We can also think of the whole process of using words $[\ldots]$ as one of those games by means of which children learn their native language. I will call these games 'language games' and will sometimes speak of primitive language as a language-game' [...] I shall also call the whole, consisting of language and the actions into which it is woven, a 'language game'. (Wittgenstein, 1953, §7).

Any encounter into a field of interest is to enter into a lifeworld. In lifeworlds, language is our medium in getting to explore and getting to know what is going on. 'Language game' is Wittgenstein's term for all the different uses of language. Different groups of people speak in different ways. Not only in different national languages such as Danish, English, or German, but also different social groups within the same national language use different language games. Footballers, surfers, sociologists etc. all have their own different language games which not only allow group members to communicate with each other, but also to confirm or prove that they are each members of precisely this or that group. When a surfer talks about a 'wipe out' the rest of us would not know that this means to fall or jump off the surfboard, but surfers would know exactly what it means because they are part of a group using a language game where the term 'wipe out' is meaningful. The same goes for footballers and sociologists who also have their special terms and expressions that only they know, use and understand.

We learn such language games by being part of a community, by following the practices of the community. Language is not a question of rule following, as we do not first learn grammar, and then try to speak: we learn a language by using it. This fact, however, is not to say that there are no rules (Lyotard, 1979, p. 9). On the contrary; being able to participate in a language game is to know how to use the rules of that language-game, but not necessarily to be able to explicitly account for these rules.

'Hence the term 'language game' is meant to bring into prominence the fact that the speaking of

language is part of an activity, or of a form of life' (Wittgenstein, 1953, § 23).

The quotes from Wittgenstein (1953) above clearly state that language is not separated from our lifeworlds, but is an integrated and constitutive part of such lifeworlds. We can do a lot of things with language. We can ask questions, we can give orders, we can tell stories, we can joke, and we can communicate with our fellow human beings. In doing so we also disclose what and who we are. Language cannot be defined as a definition would be handed out to language and language is far too complex and comprehensive to be captured in any single definition. Language is way too aporic in the same way as say life, self or love to be defined (Schanz, 1990). Instead we can talk about language games and lifeworlds. The way to learn about lifeworlds is to learn about their language games. So, the important thing here is that the student of a certain research field of interest has to learn the language games that constitute, and are constituted by, exactly that field - a lifeworld. This is the task for us as researchers: to learn the language games and thereby learn about the lifeworlds of interest.

One of the problems we face is the ability of such language games to change and develop. Lyotard (1979, p. 10) stated that every utterance in a language-game is a 'move' in that game and that this could potentially change the game. Truly so, only on very rare occasions will language games remain the same as language games constantly develop and change. Viewing a fifty-year-old movie would clearly show this: to a present day audience the language of the old movie would seem rather slow and sometimes even awkward. Language games change as lifeworlds change and lifeworlds change as language games change. These changes happen almost unnoticed in interactions between lifeworld members, but sometimes language-games and lifeworlds diverge and members of the community will either get confused and bewildered or they will have to alter their language games so that they fit the new condition of the lifeworld and they will also possibly have to change the lifeworld in some way. This is what Nørreklit (1991) calls a 'real problem': a real problem confronts the actors when their language games can no longer guide their actions in the lifeworld. With this insight we are getting closer to answering the initial question. Because if we, as researchers, were able to take part in this process of developing language games, we would then be able to assist in solving real problems - if we, following Lyotard above, were able to guide the conversation and make sure that 'every utterance in a language-game is a 'move' in that game', then the means to achieve such a substantive outcome is dialogue. Further, if we then were able to create a plausible account of this process we would be able to make that process into a substantive social scientific endeavour. But before we can do that, we need to confront the concepts dialogue and the Other. 


\section{Dialogue with 'the Other'}

'In human relations the important thing is [...] to experience the Thou truly as a Thou - i.e., not to overlook his claim but to let him really say something to us. Here is where openness belongs' (Gadamer, 1992/1960, p. 361).

The initial question was how do we do research when, at the same time, we are ourselves part of the process we are researching. With a point of departure in language games and their ability to guide actors and also, sometimes, their inability to guide actors in the course of encountering real problems, we could say that the task of the researcher is to learn about the actors' language games and thereby the lifeworld of the actors and consequently, and preferably, the 'real problems' of the actors (see e.g. Nørreklit, 1978). This now becomes the overall goal for our research endeavours.

However, as stated above, we always influence the process and precisely because of this influence we might as well influence it for the better. That is, we should listen and try to assist in solving problems throughout the encounter by assisting in developing language games in particular lifeworlds. The remedial means to achieve this positive or beneficial influence is dialogue. Using dialogue demands some specific measures. Firstly, we need an analysis of the problem(s) of 'the Other', that is, how do we understand the people we are interviewing or, as I would say, the people we are having a dialogue with? Are they interview-objects, a kind of vending machine that we can somehow extract data from? Obviously not, but what then? How can we understand and describe the Other? It follows that we need an analysis of the dialogue itself. Is it really possible to develop different language games through dialogue and thereby get to know about language games and lifeworlds? And further, would it be even possible to solve the problems caused by inadequate language games encountered in dialogue? Is dialogue really the remedy and if it is, what are the results or outcomes of such dialogue?

\section{5 'The Other'}

Theunissen (1977) notes our traditional way of seeing 'the Other' in 'transcendental philosophy' or transcendentalism after Husserl's transcendental phenomenology. In transcendentalism the other is described as an other-I, starting out with the 'I' and seeing (seeing rather literally, as transcendentalism is very much based on visual metaphors) the other as another 'I'. Much of western philosophy has gone to great lengths to criticise the Cartesian division between subject and object, be it hermeneutics, structuralism, post-structuralism, critical theory etc., but none of these has confronted this problem directly. The transcendentalist conception of the Other is problematic for several reasons. Firstly, because it is easy to see the other as an object, not as a Thou, but as an 'it'. That was the dominant philosophical critique of the Cartesian subject-object division. This division is evident in much of social science research. With questionnaires, prefabricated interview guides and theoretical vocabularies that we want to somehow 'fit' our fellow human beings into. In doing so, as social scientists, we impose language games upon people; for social scientific, as well as ethical, reasons we cannot do this as we would only deceive ourselves by not listening to the Other and simplistically trying to fit the Other into our own language games. By turning the Other into an object for our study we prevent ourselves from learning from the Other and we run the risk of reproducing our own prejudices and of not being able to improve them. But there also exists a technical problem with the subject-object division. The concept 'subject' (or the 'I') is itself a problem, no matter whether we call it Dasein, intentional actor, transcendental subject, 'I', or whatever. The concept 'subject' is not a premise but has to be derived through interpersonal encounters; that is, the subject can only be a subject when meeting or encountering the Other and thereby discovering itself as a subject.

We should, according to Theunissen, turn to a dialogical approach. The dialogue is based on the idea that the relation between I and Thou is a dialogical relation; this means that it is based on a mutual recognition grounded in language, i.e., dialogue. 'We are conversation' (Gadamer in Palmer, 2001, p. 39). That is, we are not first human (the transcendental I, Dasein, ego, subject) and then social (inter-subjectivity); rather we become human through our interaction with the Other, by being social, through our relation to others. The ' $\mathrm{I}$ ' is determined through its relation to things and to the Other. But there are, of course, differences between things and the Other. The relation to the Other is much more fundamental as it determines who we are. The 'I' does not have primacy in this relation, the 'I' and the Other are equal; both are in the encounter and this encounter between I and the Other is, therefore, a prerequisite for how we can talk about the 'I' in the first place. The Other and the 'I' constitute each other and we could, therefore, talk about the philosophy of 'the between' as the between is the fundamental 'unit' of the social world and consequently of social research. In an appendix to his book 'The Other' Theunissen provides a critical analysis of Alfred Schütz' sociology as presented in his influential book The Phenomenology of the Social World (Schütz, 1967). Theunissen concludes that Schütz is unable to appropriately conceptualise the Other because of his transcendental perspective, which starts out with the 'I' and, therefore, the Thou will always be an alien 'I' and not a Thou.

Schütz distinguishes between different worlds; umwelt, mitwelt, vorwelt and folgewelt or surrounding world, withworld, world of predecessors and world of successors respectively (Schütz, $1967 \mathrm{pp}$. 139). Theunissen finds that the question of the other is predominantly present in the umwelt, but he also identifies a problem with this: 
In the social surrounding-world (umwelt), however, the Thou should be entirely at home. In it the Other is encountered as 'fellow human being'; in the social with-world (mitwelt), simply as 'contemporaries' (nebenmensch). Functioning as the original norm for the understanding of the with- predecessor-, and successor- worlds, it (the surrounding world) has its own centre in the 'environmental social relation', the characteristic of which Schütz takes to be dialogical 'reciprocity'. The entire environmental (umweltliche) experience of the alien is, however, distinguished from the with-worldly through its 'immediacy' (Theunissen, 1984, p. 346).

From this Theunissen concludes that the Schützian 'Thou' is meaningless in the sense that it has two very different conceptions, both of which are deemed to be insufficient when conceptualising the Other. It is both 'every other' and 'only the other' in the surrounding world. Theunissen continues:

'Still, in both senses, the word 'Thou' is exclusively directed towards the 'alter ego'. This 'Thou', therefore, is dialogically irrelevant' (Theunissen, 1984, p. 346).

Theunissen rejects Schütz' attempt to conceptualise the Other, because Schütz remains trapped within the transcendental scheme of the 'I' as the starting point for any conceptualisation of the relationship to the Other. But Theunissen has more; because of the 'solipsist transcendentalism' (Theunissen, 1984, p. 347) it becomes difficult for Schütz to achieve his own goal of finding a way for the sociologist to study the social world. He is unable to conceptualise 'the between' because he is caught in the experience of the alter ego, hence the Other will always remain an alien I.

\section{What is in it for our research? Gadamer and Dialogue}

Even if we could place Gadamer firmly within the dialogical paradigm, based on his analyses of dialogue in Truth and Method (1992/1960), he later criticised the dialogical approach heavily, though not necessarily very successfully (Vessey, 2005), possibly to guard Heidegger's Mitsein (Being-with) against the critiques from Martin Buber (Olesh, 2005) and later from Theunissen (1984). It appears that Gadamer prefers an Aristotelian conception of friendship and phronesis to the I-Thou and The Between, which he calls 'an instantiation of the Other' (Gadamer, 2000). Notwithstanding such criticism it is not too difficult to base an analysis of dialogue on Gadamer's account of dialogue in Truth and Method (1992/1960, p. 367).

Dialogue is well described as a research method in earlier work (see Henriksen et al., 2004, pp. 152-161). Based on Theunissen's critique of transcendentalist paradigms and Gadamer's analysis of dialogue we can now turn to the consequences of this approach for social research. Within the transcendentalist paradigm it is, according to Theunissen, impossible to conceptualise a social ontology. The consequences of this inability to conceptualise the Other and dialogue for any social research endeavour is that the social will always remain a mystery. We must look again at the distinction between interviews and dialogues.

Dialogue implies conversation and is based on language; it is addressive, meaning that when we engage in a dialogue we meet the Other on an equal footing - we address the Other (Code, 2002). The interview, on the other hand, is perceptive or observational, meaning that we establish a distance to the situation and, even worse, we might deceive ourselves into believing that we are outside the situation and observing it objectively. We do not perceive, but we engage in a dialogue, we do not see or observe, but we are in a dialogue. Language is the medium. The Other is not an object or a medium for obtaining answers, but is a partner in a conversation: remember the Gadamerian mantra: 'We are conversation'.

The question now is whether we, as social scientists, are able to somehow assist in solving problems, real problems, through the development of language games and if dialogues are the means of doing so? Gadamer's analysis of dialogue, as it is found in Truth and Method, can possibly point to some of the answers to this question:

What characterises the dialogue, in contrast with the rigid form of statements that demands to be set down in writing, is precisely this: that in dialogue spoken language - in the process of question and answer, giving and taking, talking at cross purposes and seeing each other's point - performs the communication of meaning that, with respect to the written tradition, is the task of hermeneutics (Gadamer, 1992/1960, p. 368)

'The maieutic productivity of the Socratic dialogue, the art of using words as a midwife, is certainly directed towards the people who are the partners in the dialogue, but it is concerned merely with the opinions they express, the immanent logic of the subject matter that is unfolded in the dialogue'. (Gadamer, 1992/1960, p. 368)

Using word as midwife is about working out a joint or common meaning and also about both parties asking questions and giving answers. This is in contrast to the interview where the questions are directed towards the interviewee and the 
answers are directed towards the researcher. This, of course, requires some skill on the part of the researcher. Firstly, the skill of asking and answering and as a consequence of this dialogic process the researcher also needs to know, and know a substantive amount, about the case in question (Sachverstehen, Gadamer, 1992/1960, p. 95) as to understand is to understand something. It follows that the researcher needs to be well prepared in order to be able to ask good questions and to provide good answers.

'What emerges in its truth is the logos, which is neither mine nor yours and hence so far transcends the interlocutors' subjective opinions and even the person leading the conversation knows that he does not know.' (Gadamer 1992/1960, p. 368).

Again, it is the common meaning that is of most interest here - not mine, not yours. Through the dialogue we should transcend our subjective meanings and work out a common meaning that can be expressed in new and better concepts, in a new or improved language game and thereby we can try to assist in solving the real problems of the actors involved in their lifeworlds.

'As the art of conducting a conversation, dialectic is also the art of seeing things in the unity of an aspect (sunoran eis hen eidos) i.e., it is the art of forming concepts through working out the common meaning.' (Gadamer 1992/1960, p. 368).

With new 'moves' (Lyotard) resulting in new concepts (Nørreklit), we should preferably end up with a new and improved language game; a language game which is simply better at addressing or handling new situations in the lifeworld of the actors involved in the dialogue.

'Openness to the other, then, involves recognising that I myself accept some things that are against me, even though no one else forces me to do so.' (Gadamer, 1992/1960, p. 361).

But all this, of course, requires real openness to the Other, that we as researchers are actually listening and not just interviewing seeking to confirm our prejudices, but listening and trying to improve our prejudices.

The only question remaining now is, how do we make an account of all this? This is no different to any other ethnographic, anthropological or social science method: field notes, recording of the dialogues, transcriptions, analyses, etc. And the results could be handed back to the Other in new dialogues, in meetings, in workshops etc. (see Henriksen et al., 2004, pp. 145ff; and for a very successful application of the method see Nørgaard, 2013).

\section{Conclusions}

'How do we make a scientific account of a process that we are, ourselves, part of?' As a research method the dialogue has several advantages over, let's say, interviews. First of all, in light of Theunissen's critique of transcendentalism we avoid the problem of making the Other into an object for questioning, expected to answer our questions, and possibly simply confirming our prejudices. The dialogue collapses the distinction between researcher and actor thus making us partners in a conversation. The dialogue may be described with the distinction between 'perceptive' and 'addressive'. By being addressive we take the Other seriously and through the openness of the dialogue are actually able to learn and not simply confirm our existing prejudices. Through the dialogue we not only learn about language games and gain access to lifeworlds but we are also now able to avoid the traditional research situation where we just take, write and publish. Now we can give something back to the real people who lend us their time and their stories. So, with the dialogue and by taking the Other seriously, we are in fact able to do research in which we ourselves play an active part. This is not a problem; rather, it is a much more ethical way of doing research.

\section{References}

Code, L. (2002). Feminist interpretations of Hans-Georg Gadamer. Penn State University Press.

Gadamer, H.-G. (1992/1960). Truth and Method. Crossroads.

Gadamer, H.-G. (2000). Subjectivity and intersubjectivity, subject and person. Continental Philosophy Review. 33 , pp. $275-287$.

Henriksen, L. B. et al. (2004). Dimensions of change. CBS press

Latour, B. (1999). Pandora's Hope - Essays on the Reality of Science Studies. Harvard University Press, Cambridge Massachusetts.

Lyotard, J.-F. (1979). The Postmodern Condition: A Report on Knowledge. Manchester University Press. Manchester.

Nørgaard, B. (2013) Disclosing New Worlds in Continuing Education. Aalborg University, Department of Planning. 
Nørreklit, H. (1991). Virksomhedens Problemerkendelse (The Company’s Recognition of Problems). Djøf Publishing.

Nørreklit, L. (1978). Problem orienteret forskningspraksis og den reale virkeligheds constitution. (Problem oriented research practice and the constitution of the real reality). Aalborg University Press. Aalborg.

Olesh, A. (2008). Martin Buber's Critique of Heidegger Being-with: An exploration of a disagreement between two of the most important thinkers of the 20th century. Conference proceeding, Oneonta, New York.

Palmer, R. E. (2001). Gadamer in conversation - Reflections and Commentary. Yale University Press. New Haven.

Schanz, H.-J. (1990). Forandring og Balance: reflectioner over metafysik og modernitet (Change and Balance: reflections on metaphysics and modernity). Aarhus, Modtryk.

Schütz, A. (1967) The Phenomenology of the Social World. Northwestern University Press.

Theunissen, Michael (1984) The Other - Studies in the Social Ontology of Husserl, Heidegger, Sartre, and Buber. MIT Press.

Vessey, D.(2005) Gadamer's Account of Friendship as an Alternative to an Account of Intersubjectivity. Philosophy Today. Vol. 49/5, pp. 61-67.

Wittgenstein, L. (1953) The philosophical investigations. Macmillan. London. 